convinced that the diet of even the mildest cases of glycosuria should be regulated by careful aud complete urinary analyses and be so adjusted that no avoidable strain is thrown upon the metabolic powers of the patient in any direction. The appearance of amino-acids in the urine in recognisable amounts is usually a sign that too much protein food is being taken, just as the presence of sugar is an indication that more carbohydrate is being consumed than the patient can deal with efficiently. Their persistent increase, in spite of careful dieting, is of bad prognostic significance, but a steady diminution following a regulation of the protein intake suggests that, with care, the life of the patient may be prolonged for months or even years.

Nottingham-place, $w$.

\title{
THE MORTALITY OF CHILDREN FROM BURNING.
}

BY WILLIAM A. BREND, M.A. CAMB., M.B., B.Sc. LoND., LECTURER ON FORENSIC MEDICINE, CHARING CROSS HOSPITAL.

THE deaths here examined are those of infants and children from burning caused by ignition of clothing, lamp accidents, and, in the words of the Registrar-General, "otherwise or not stated how," the great bulk of which may be assumed to have been due to the catching fire of clothing. The following are the actual figures for the years 1906 to 1911:-

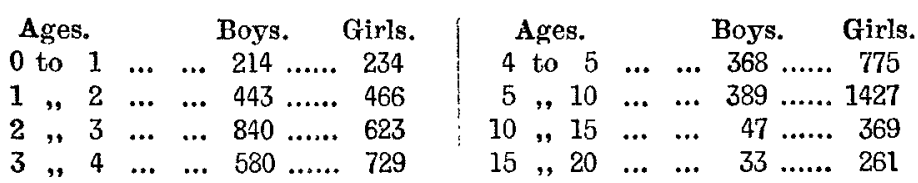

In the subjoined chart a small correction has been made for the slightly greater number of boys at the earlier ages than girls. It will be seen that there is a very marked difference between the mortality of boys and girls. In the case of boys the figures increase rapidly up to the age of 3 , drop nearly as quickly to the age of 6 , and then gradually fall away to almost nothing. The mortality of girls continues to increase up to the age of 5 , and then declines, though to not nearly the same extent as among boys. It remains higher through the ages of adolescence, being between the ages of 15 and 20 about eight times as great. TheArS
is probably due to the difference in the style

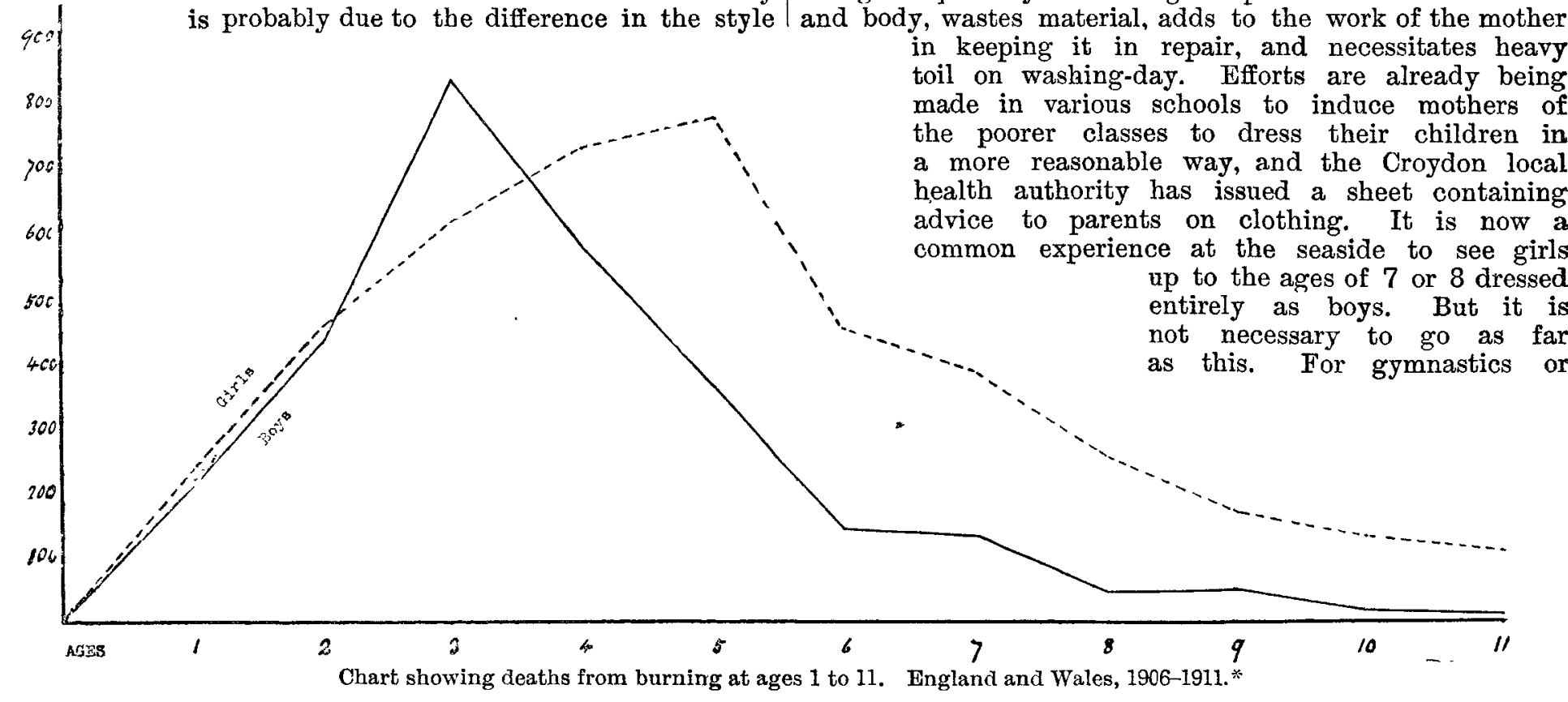

of clothing worn by the two sexes. Up to about the age of 3 boys are dressed in the same way as girls. From 3 to 4 they are put into male attire and there is an abrupt and marked fall in the mortality from burning. With girls it is not until the age is reached at which they are better

* I am indebted to the Registrar-General for the details of figures for the ages 5 to 11 . able to take care of themselves that the figures show a decline, though eren then, and for later years, they remain much higher than those relating to boys.

Miss Synge, in her admirable book on children's clothing, has recently drawn attention to the excessive number of garments worn by children of the poorer classes. Speaking of her experience in schools she writes: "The quantity of material used on the children was pitiful. Early Victorian patterns were for the most part used, and underneath the pleats and gathers the children looked swollen and shapeless. ...... The girls are the worst off. First they wear a thick vest and bunchy flannelette chemise. Flannelette drawers over or under some sort of stays-often boned-follow. Then two or three petticoats gathered or pleated into a waistband, or more often attached to a body or two bodies, not infrequently three bodies, of varying sizes. Over this is a bunchy frock, often kilted, and a pinafore. The garments are of varying sizes, some much too tight, some too large, and there is little freedom of limb such as we would see."

Probably no more inflammable arrangement than this, consisting of layers of flimsy material separated by air, could be devised. The corner of a pinafore has only to become ignited and in a moment the little victim is a mass of flames. On the other hand, the inflammabilit of a boy's costume consisting of cloth knickers and jersey or coat is far less.

Considerable agitation has been directed against the use of flannelette, which is very largely worn, and undoubtedly the cheapest varieties are to be avoided. But this material is inexpensive, and it would probably be difficult to substitute anything fer it among the poor. The foregoing figures show that it is not so much the material as the style of clothing: which leads to loss of life, and probably any other light material used in the present fashion would be almost as dangerous.

The reason for the higher mortality of boys as compared with girls between 2 and 3 is not quite clear, but it may be due to boys at this age being rather more vigorous and enterprising than girls, and more frequently getting into positions of danger. It might be suggested that the higher mortality among girls at later ages is partly due to their being kept more at home and engaged in culinary work. But against this must be set the greater tendency of boys to play with matches or fire.

In addition to its inflammability there are other reasons for condemning the present manner of dressing little girls. The great quantity of clothing hampers the freedom of limb and body, wastes material, adds to the work of the mother in keeping it in repair, and necessitates heavy toil on washing-day. Efforts are already being in various schools to induce mothers of Croydon local advice to parents on clothing. It is now a common experience at the seaside to see girls up to the ages of 7 or 8 dressed entirely as boys. But it is not necessary to go as far as this. For gymnastics or

drilling a costume is now worn in many schools consisting of navy serge knickers and a short tunic or jersey and plain serge skirt. This costume is becoming, serviceable, and hygienic, and does not subject the wearers to the risk of injury or death in one of its most terrible forms. These are strong reasons for encouraging its use among the poorer classes in every way possible. 


\section{ittedical Sorteftits.}

\section{ROYAL SOCIETY OF MEDICINE.}

\author{
SECTION OF PSYCHIATRY.
}

Pellagra with Insanity. - What is Insanity?

A MEETING of this section was held on Oct. 28th, Sir George SAVAGE, the President, being in the chair.

Dr. J. W. E. COLE demonstrated a case of Pellagra with Insanity. The patient was a woman who three days after admission to a mental hospital developed an erythema on the bridge of the nose, and this rapidly spread over certain parts of the face. Three weeks later the affected area was covered with a dry, yellowish-brown stain. The scaly surface had a clearly defined red margin, was very symmetrical in distribution, and resembled in every respect a case of severe sunburn. The backs of the hands were deeply pigmented and the epidermis was very rough and coarse. She had a dysenteric form of diarrhoea, but no stomatitis. Her reflexes were definitely exaggerated, but ankle clonus was absent. Her mental condition was difficult to distinguish from dementia præcox. The rash was now disappearing, and with it the mentality was improving. She had been in the asylum, on and off, four years, but the rash had not previously appeared.

Dr. Charles A. Mercier read a paper entitled "What is Insanity?" He said there existed a vague notion of what was meant by insanity, but the fact that this notion had not been satisfactorily reduced to words showed that the concept was unprecise. Insanity and unsoundness of mind were not convertible terms. Each included much which was not in the other ; in fact, the two things coincided for only part of the way. Insanity was a disorder not only of mind but of conduct ; giddiness, epileptic auræ, claustrophobia, and agoraphobia had nothing to do with insanity. No one dare call a man insane until he had examined his conduct and found it disordered. And in speaking of disorder of conduct he did not mean "disorderly conduct" in the police court sense. But disorder of brain function might be added to the concept, making it a threefold matter; also disorder of metabolism deserved a place, making it fourfold. Each of these concepts was right in its own connexion; confusion ensued from giving all the concepts the same name. If insanity meant disorder of conduct and mind alone, then insanity was a symptom of disorder of brain function. If insanity meant disorder of conduct and mind plus disorder of brain function, and if these three were correlated disorders from which the patient suffered, then the three disorders constituted the disease insanity. But if these three were correlated with some wider disorder, such as alcoholic poisoning, myxœdema, gout, specific fever, Graves's disease, this threefold disorder was a sub-disease of the wider disease. When insanity was a symptom only he argued that it was expedient to speak of it as delirium, reserving the name "insanity" for cases in which what was meant by it was a disease.

The paper was discussed by the President, Mr. JAMes Stewart, Dr. Percy Smith, Dr. Ernest Jones, and Dr. F. S. Pasmore, and Dr. Mercier replied, elaborating his thesis still further.

\section{DEVON AND EXETER MEDICO-CHIRUR- GICAL SOCIETY.}

\section{Chronic Abdominal Pain.}

A MEETING of this society was held at the Royal Devon and Exeter Hospital on Oct. 10th, Dr. C. J. VLIELAND, the President, being in the chair. In response to an invitation from the council of the society an address was given by Mr. T. Crisp ENGLISH, who had chosen for his subject "Chronic Abdominal Pain." Mr. Crisp English dealt mainly with the cases in which the cause of the pain was not at first obvious, and in which the question of a laparotomy usually arose. $\mathrm{He}$ said that these cases were becoming increasingly common, both in private and in hospital practice. The private patient who had had attacks of

1 THE LANCET, Sept. 6th, 1913, p. 717. pain for some time, in spite of various forms of medical treatmont, was sooner or later sent to the surgeon for an opinion; hospital patients were constantly arriving with notes saying that the bearers had had a chronic pain and advising that they should be opened. There was no group of cases in which good sound judgment and common sense were more needed. On the one hand, many patients might be saved years of chronic abdominal pain and illhealth by operation; on the other hand, many patients had been plunged into hopeless invalidism by an ill-considered laparotomy. Speculative operations frequently led to disaster, and were often the forerunner of further operations upon patients who never seemed to get well and who were always ready to have yet another organ explored or excised; but in most cases of chronic abdominal pain there was a definite organic cause for the pain, which could be removed by operation, and if the effects of the pain justified operative measures, then operation should be advised. The most important point was that a thorough physical examination must be made before the best line of treatment was decided upon. Not until evidence of every possible kind had been collected and summarised should diagnosis and treatment be discussed. In this the surgeon must rely upon the coöperation of the medical practitioner and the physician. In hospital practice the diagnostic process was easily arranged, and the following was the usual procedure, say in the case of a patient who had chronic or recurrent abdominal pain, the cause of which was not at first obvious. The history of the case was carefully taken, and the usual physical examination made. The urine was measured for 24 hours and analysed. If there was any doubt about the kidneys or bladder a bacteriological examination was made, for a coli pyelitis was the cause of some cases of obscure pain in the side. Skiagrams were then taken, either of the urinary tract to exclude stone, or of the alimentary tract after the ingestion of a bismuth meal. The patient was referred to the physician in many cases; in doubtful stomach cases a test meal was given and the result analysed. In certain other cases also special investigations were carried out, such as examination with the sigmoidoscope or cystoscope or a blood examination. Further, there might be a difficulty in properly examining the abdomen or pelvis, and an examination must be made under an anæsthetic. There should always be clear definite reason for an examination under an anæsthetic, and it should never be done on the off-chance that something might turn up which could not be discovered without it. The various reports and analyses were brought together after three or four days and these clinical findings were considered as a whole. In this way the diagnosis ana treatment could be discussed under the best possible circumstances. Wealthy patients might also have a thorough investigation, but the man of moderate means often could not enjoy the advantages open to the rich and poor, and in his case the question of expense very often meant a limited investigation; this was obviously a matter which urgently needed reform. In taking the history of the illness, the important point was to be quite clear as to the very beginning of the illness : when was the patient last in quite normal health? what was the very first symptom he noticed ? The initial symptoms should be gone into carefully and fully, and these would often suggest a clue which could not be picked up in the latter part of the history. The examination of the abdomen should never be hurried. They should look and think before they felt, especially in children. The well-known picture of "The Doctor," by Sir Luke Fildes, expressed perfectly what should be the attitude of the medical man towards the sick child: watching and thinking, and realising that much might be learned whilst the child slept. Skiagrams of the alimentary tract might give very valuable information, but one must confess that in the bulk of cases of chronic abdominal pain they were apt to be disappointing. A great deal had yet to be learned about the meaning of the skiagraphic appearances. Deductions made from skiagrams were often falsified when the abdomen was opened, and skiagrams should only be considered in conjunction with other means of investigation. In reviewing the cases of abdominal pain one noticed at once that there were certain well-marked types and groups. There was the gastric group of cases; there were the men with pain in the right upper abdomen; there were the women with pain in the right side; there were those with suspected appendices; there were the elderly, who might have 